\title{
Protection Parameters against the Cracks by the Method of Volume Compensation Dam
}

\author{
Georgiy Bulatov ${ }^{1}$, Yulia Ibraeva ${ }^{1,{ }^{*}}$, Philipp Tarasevskii ${ }^{1}$, Xeniya Rakova $^{1}$ and Danijela \\ Zejak $^{2}$ \\ ${ }^{1}$ Peter the Great St.Petersburg Polytechnic University, 195251 St. Petersburg, Russian Federation \\ ${ }^{2}$ University of Montenegro, 81000 Podgorica, Montenegro
}

\begin{abstract}
This article provides estimates the parameters of protection from cracking dam due to volume compensation method. This article discusses the method of compensation dam volume. This method allows calculating the settings of security causing cracks the dam. Presents graphs of horizontal deformations of elongation calculated surface along the length of the construction and in time. Showing horizontal stress distribution diagram in the ground around the pile in plan and in section. Given all the necessary formulas for the method of compensation of the dam volume.
\end{abstract}

\section{Introduction}

Dam it is an important water works. The damage caused by its failure could be extremely high. Due to the fact that the destruction of direct construction of the dam is often only a small part of the total damage, which included losses from the destruction of associated facilities because the dam is almost always the only part of the waterworks, loss of enterprise. The production of which may be paralyzed as a result of the termination of revenues from hydroelectric power stations, the losses from the devastation produced disastrous spillway downstream of the dam. Global destruction of the dam begins to crack formation. Therefore, of particular relevance is the theme of protecting the dam from the emergence of the weakened areas.

\section{Experimental methods}

Experimental methods discussed in this article is a method of dam volume compensation. The method consists in the fact that additional volumes in the form of piles or jacks, which periodically introduced into the ground are compensate the deficit of its volume, which arises when dam is lengthening and thus protect it from excessive loosening, and faults cracks [1-9]. To protect the dam by this method in the extension zone of peak strain produced piling on the crest of the dam for the repayment or reimbursement deformations of the first period. Pile made proactively in time, for example, a month before it reaches peak levels strain the permissible value. Then, with the growth of the deformation of the earth surface at the crest will be set a new high elongation strain, which will also be repaid or compensated stemming piles of the second period of strain. Thus, by plunging into the 
dam of additional volumes of piles will be compensated strain elongation until their complete decay that will exclude completely the possibility of threatening the dam cracks.

\section{Experimental section}

It have been known that the relative volume deformation is equal to the amount of linear deformation along the axes

$$
\varepsilon_{v}=\varepsilon_{x}+\varepsilon_{y}+\varepsilon_{z}
$$

In the case of displacement soil due to piles in the horizontal plane of the necessary increase (expansion) of the surface at the crest part of the dam determined from expression

$$
\varepsilon_{s}=\frac{\varepsilon_{\mathrm{p}}}{\eta_{\mathrm{H}}}
$$

Where $\varepsilon_{\mathrm{p}}$ - the expected deformation elongation dam from undermining and other effects on settlement dangerous surfaces such as level of filling storage, $\eta_{\mathrm{H}}$ - the degree of orientation of the ground prop (for conventional piles -0.5 for piles with a special tip for targeted soil prop - 0.7 , for piling (tongue) the ranks - 0.9).

$$
\varepsilon_{p}=\varepsilon^{*}+\frac{\Delta R}{R^{*}}+\varepsilon_{g p}
$$

Where $\varepsilon^{*}$ - the expected deformation elongation of the calculated earth's surface (WHR) from undermining, $R^{*}$ - radius of its curvature, $\Delta R$ - the exceeding of estimated dangerous surface above the WHR, $\varepsilon_{g p}$ - deformation elongation from other than the undermining affects to the dam.
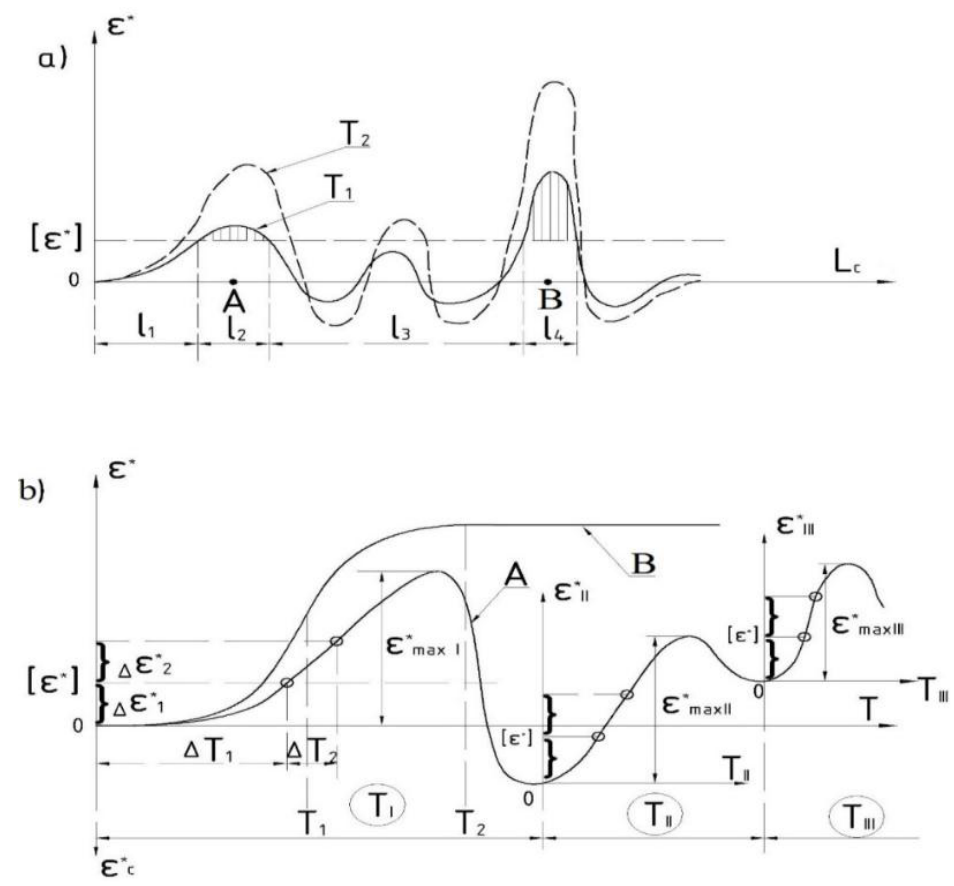

Fig. 1. Changing the horizontal deformations elongation of calculated surface: a - by structures length, $b$ - in time. 
Square section piles (or the value of the increment section of jacks or injection) required to secure compensation horizontal extensions the dam, written as

$$
S_{r}=\Omega_{r} \cdot \varepsilon_{s} \cdot K_{u n} \cdot\left[K_{s . \mathrm{p}}\right]
$$

Where $\Omega_{r}$ - the surface area of the ridge, for one pile (or a jack or an injection well), defined step piles or their rows, $K_{u n}$ - coefficient unevenness of sealing between the pile space (approximately equal to 1.5 - for distributed piles and 1.2 - for a pile rows), $\left[K_{s . p}\right]-$ admissible generalized coefficient stock for the dam under the deformations of its elongation (approximately equal to 1.5 ... 2.0) [10-14].

Dosed application with the growth of strain elongation the dam crest it is feature of protective measures. For its implementation carried out systematic forecasts and instrumental measurements of deformation.

If now the dashed cut level allowable deformation $\varepsilon^{*}$, it is possible to select, for example, at the time $T_{1}$, portions on which the strain exceeded (shown by vertical hatching) of the permissible level. These sections of dam had to be adequately protected from destruction at the time of $T_{1}$. At the time, needed $T_{2}$ has other security parameters, and at other sites. From observing practices for the displacement of rocks, it is known that the Earth's surface deformation has pronounced maxima (Fig. 1a) in the form of relative deformations of elongation of the Earth's surface.

On the Figure 1b shows the change in strain in time for the points A and B of considered structures. At the same time, the deformations can change very unevenly, and even change, the sign on the opposite (a curve for point "a"). On the curves can be distinguished several deformation stages $\Delta \varepsilon^{*}$, each of which will be equal to the allowable strain $\left[\varepsilon^{*}\right]$, and, accordingly, set aside as much time periods $\Delta T_{i}$ development of each of these stages of deformation [15-18].

The onset of each of the periods of strain have been defined due to prognosis and can be monitored during operation of facilities geodesic measurements on two alignments, one of which is laid on the crest of the dam, and the other at the foot of the lower slope. The frames we recommend laying in increments of $5 \ldots 10 \mathrm{~m}$.

To protect the dam by this method in the peak area of elongation strain (Fig. 1a) produced piling on the crest of the dam for the repayment (reimbursement) deformations of the first period. Pile made proactively in time, for example, a month before it reaches peak levels strain the permissible value.

Then, with the growth of the deformation of the earth surface at the crest will be set a new high elongation strain, which have been also repaid (compensated) stemming piles of the second period of strain [18-21].

Thus, by plunging into the dam of additional volumes of piles will be compensated all strain elongation until the moment of their complete damping that will completely exclude the possibility of appearance the hazardous cracks for the dam [22-26].

In the case of a complex deformation WHR over time as, for example, it is shown in the graph to the point $\mathrm{A}$ in Fig. $\mathrm{b}$, the whole period $\mathrm{T}$ is divided into cycles of deformation, boundaries are points corresponding to the minimum elongation strain. For points $\mathrm{A}$, there are three such cycles, and total elongation strain, which has to be repaid (offset) of the periodic harvesting, will be

$$
\varepsilon_{\max }^{*}=\varepsilon_{\max I}^{*}+\varepsilon_{\max I I}^{*}+\varepsilon_{\max I I I}^{*}
$$

Accordingly, the total period of strain will be

$$
T=T_{I}+T_{I I}+T_{I I I}
$$


However, more preferred is a separate consideration of each cycle of deformation as a single act (the impact of) of undermining, with a corresponding development of protective measures, which, in principle, in different cycles may be quite different. Wherein it is possible multi directional impact protection measures on the course of deformation WHR in subsequent cycles.

In this case, the strain compensation piles subsequent compression deformation will be difficult. The number of periods piling on the considered deformation area is

$$
n_{\mathrm{T}}=\frac{\varepsilon_{p}}{\left[\varepsilon_{p}\right]}
$$

Where $\left[\varepsilon_{p}\right]$ - allowable deformation elongation of ground on the surface settlement.

$$
\left[\varepsilon_{p}\right]=\frac{\varepsilon_{c r}}{\left[K_{p}\right]}
$$

Where $\varepsilon_{p}$ - the limiting extensibility of the soil, which can be accepted as from the condition of preventing so with taking into account the limited size of cracks assumptions on the estimated dangerous surface.

Sectional area of one pile for immersion in each period of develop and deformation compensation will be

$$
S_{p l}^{I}=\frac{S_{p l}}{n_{T}}
$$

The depth of immersion of piles

$$
H_{p l}=h_{c r . l i m} \cdot\left[K_{\text {s.p }}\right]
$$




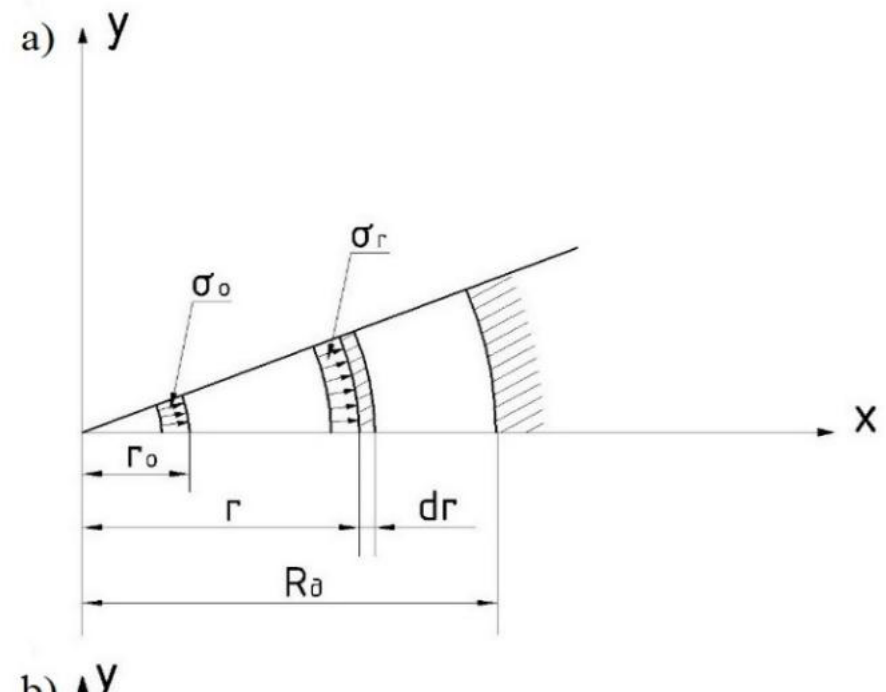

b) $4 y$

Fig. 2. The distribution of horizontal stress in the soil around the pile: $\mathrm{a}$ - in plane, $\mathrm{b}$ - a sectional.

Where $h_{\text {cr.lim }}$ - maximum depth of crack propagation.

When submerged pile adjacent soil is pushed in the radial direction and compacted. To estimate the horizontal radial stresses in axisymmetric problem use the first part of the formula, shown in the book, which write Yaropolskii I.V.

From this formula is obtained the approximate dependence of the compressive horizontal stress in the soil around the pile (Figure 2)

$$
\sigma_{r}=\frac{r_{o}}{r} \cdot \frac{E_{\text {com }}}{\pi\left(1-\mu^{2}\right) \ln \frac{R_{d}}{r_{o}}}
$$

Where $r_{o}$ - sectional radius of the pile, $E_{\text {com }}$ and $\mu$ - modulus of deformation compression and coefficient Poisson for soil around the pile, $r$-the distance from the point considered in the soil to the pile axis, $R_{\mathrm{d}}$ - the radius of the deformed zone of soil around the pile at her pile, taken equal to half the maximum distance between adjacent piles [25-27].

Soil compression is considered adequate, provided 


$$
\sigma_{r}=\sigma_{R d} \geq\left[\sigma_{r e q}\right]
$$

Where $\left[\sigma_{\text {req }}\right]$ - required compressive stress in the ground, that preventing disclosure of through cracks (in the first approximation is taken equal to $0.01 \mathrm{MPa}$ ).

\section{Results and Discussion}

The result of the article is the parameters by which, in the earth dam are determined safe work. All required dependencies have been obtained. Received the formula have been calculated the adequate soil compression.

\section{Conclusion}

Security is the one of the important criteria for facilities operation. In many ways, it depends on the mechanical processes occurring in the structure. The most common cause is the destruction of the dam it is a cracks. Cracking entails global destruction in dam, thus the prevent appearance of cracks and rendering options cracks that already been formed it is highly important topic. This subject have not been elaborated until the end and need to continue research in this direction.

\section{References}

1. R. Usmanov, M. Rakočević, V. Murgul, N. Vatin, Applied Mechanics and Materials, 633-634, (2014)

2. R. Usmanov, I. Mrdak, N. Vatin, V. Murgul, Applied Mechanics and Materials, 633634, (2014)

3. M. Jocovic, B. Melovic, N. Vatin, V. Murgul, Applied Mechanics and Materials, 678, (2014)

4. Sonoda, Y.,Applied Mechanics and Materials, 566, (2014)

5. E. Panulinová, S. Harabinová, Advanced Materials Research, 969, (2014)

6. S. Harabinová, E. Panulinová, Advanced Materials Research, 969, (2014)

7. M. Sharp, Y. Seda-Sanabria, E. Matheu, Applied Mechanics and Materials, 82, (2011)

8. Mrdak, M. Rakočević, L. Žugić, R. Usmanov, V. Murgul, N. Vatin, Applied Mechanics and Materials, 633 - 634, (2014)

9. D. Kubečková, Advanced Materials Research, 1020, (2014)

10. G.Y. Bulatov, V.I. Teleshev, V.A. Leonov, Fil'tratsionnyye issledovaniya i raschety, 7, (1983)

11. D. Hilyard, The dam safety minefield, International Water Power \& Dam Construction. 5 (2010)

12. S.V. Bortkevich, Power Technology and Engineering, 5, (2009)

13. A.B. Feringer, N.V. Kabanov, Power Technology and Engineering, 46(5), (2013)

14. N. Vatin, N. Lavrov, N. Korzhavin, Applied Mechanics and Materials, 641-642, (2014)

15. V.B. Vladimirov, Y.K. Zaretskii, V.B. Orekhov, Power Technology and Engineering, 3, (2003)

16. S.Y. Shkolnikov, I.A. Sekisova, Power Technology and Engineering, 5, (2008)

17. V.N. Bukhartsev, M.R. Petrichenko, Power Technology and Engineering, 46(3), (2012)

18. G.Y. Bulatov, Trudy LPI, 375, (1981)

19. V.S. Istomina, V.V. Burenkova, G.V. Mishurova, Stroyizdat (1975) 
20. A.K. Bougrov, V.F. Markevich, Gidrotekhnicheskoye stroitel'stvo, 4, (1980)

21. G. Bulatov, N. Vatin, D. Nemova, Y. Ibraeva, P. Tarasevskii, Applied Mechanics and Materials, 725-726, (2014)

22. V. Deković, A. Andelković, N. Milošević, G. Gajić, M. Janić, Carpathian Journal of Earth and Environmental Sciences, 8 (2) , (2013)

23. L.N. Rasskazov, M.V. Smirnova, Power Technology and Engineering, 48 (2) , (2014)

24. L. Svatovskaya, A. Sychova, M. Sychov, V. Okrepilov, MATEC Web of Conferences, 53, Article Number 01023 (2016)

25. J. Guo, I. Hasan, P.W. Graeber, Springer Series in Geomechanics and Geoengineering, 2015, (2014)

26. K. Krayushkina, O. Prentkovskis, A. Bieliatynskyi, J. Gigineishvili, A. Skrypchenko, A. Laurinavičius, K. Gopalakrishnan, J. Tretjakovas, Baltic Journal of Road and Bridge Engineering, 11 (1), (2016) 